\title{
RAPD of controlled crosses and clones from the field suggests that hybrids are rare in the Salix alba-Salix fragilis complex
}

\author{
LUDWIG TRIEST*†, BART DE GREEF†, RUTH DE BONDT† \& JOS VAN SLYCKEN $\ddagger$ \\ $\dagger$ Laboratorium voor Algemene Plantkunde en Natuurbeheer (General Botany and Nature Management), \\ Vrije Universiteit Brussel, Pleinlaan 2, B-1050 Brussels, Belgium and $\ddagger$ Jos Van Slycken, Institute for Forestry \\ and Game Management, Ministry of the Flemish community, Gaverstraat 4, 9400 Geraardsbergen, Belgium
}

\begin{abstract}
The polyploid Salix alba-Salix fragilis hybrid complex is rather difficult to study when using only morphological characters. Most of the features have a low diagnostic value for unambiguously identifying the hybrids, introgression patterns and population structures, though morphological traits have proved to be useful in making a hybrid index. Morphology and molecular variation from RAPDs were investigated in several case studies on willows from Belgium. A thorough screening of full-sib progenies of interspecific controlled crosses was made to select homologous amplification products. The selected amplified products proved to be useful in a principal coordinate analysis for the estimation of variability of hybrid progenies. On the basis of genetic similarities and ordination analysis, a method for the identification of clones in the field was established using presumed pure species and presumed introgressants. The chosen reference clones were checked against additional European samples of putative pure species to ensure the reliability of the method beyond a regional scale. The RAPDs suggested that both species have kept their gene pools well separated and that hybridization actually does not seem to be a dominating process. The observation that molecular markers do not always follow the morphological traits or allozyme data is discussed.
\end{abstract}

Keywords: genetic diversity, hybridization, polymorphism, RAPD, Salix alba, Salix fragilis.

\section{Introduction}

Salix alba L. (white willow), Salix fragilis L. (crack willow) and their hybrid $S . \times$ rubens Schrank are closely related polyploid species $(2 \mathrm{x}=76)$ with a widely sympatric distribution throughout Europe. They are dioecious but may reproduce as well sexually as by vegetative propagation. The willows are typical treeforming pioneer species in alluvial plains and riparian zones. The delimitation between these polyploid taxa relies on relatively few diagnostic features in the morphology. Consequently, large overlaps exist which make it difficult to identify samples from the field unambiguously. In many cases the two species coexist in mixed stands. Artificial hybridization is possible, but the taxonomic identity as well as the identification of their metapopulations remains difficult. Different elements such as the lack of qualitative diagnostic characters, the frequent occurrence of intermediate morphological

*Correspondence. E-mail: 1triest@vub.ac.be forms and the successful interspecific controlled crosses, support the hypothesis that $S$. alba and $S$. fragilis may hybridize frequently in nature. Hybrids and introgressed hybrids seem to dominate in the field when considering morphology (De Bondt, 1996).

Few studies on allozyme variation in Salix species have been performed, but they have already shed some light on the genetic structure of diploid and polyploid willow populations. In $S$. silicicola Raup. and $S$. alaxensis (Anders.) Cov. $(2 \mathrm{x}=38)$ from North America, the differentiation between populations was low and the estimates of gene flow based on $G_{\mathrm{ST}}$ values were rather moderate (Purdy \& Bayer, 1995). This is consistent with the reviewed data on trees with a dioecious breeding system and wind-dispersed seeds (Hamrick \& Godt, 1989). Factors that promote high levels of genetic diversity within populations in Salix species include dioecy, high fecundity, wind-dispersed seeds and long-lived clonal growth. Characteristic for Salix might be the allelic evenness of allozyme distribution (Brunsfeld et al., 1991) as well as the low probability of genetic drift (Purdy \& Bayer, 1995). Allozymes 
in full-sib controlled crosses of polyploid $S$. alba and $S$. fragilis from Belgium showed Mendelian segregation for certain enzymes, whereas other genes had fixed heterozygosity. Most of the enzymes could not be used as good markers at the species level because differences were mainly in allele frequencies (Triest et al., 1998a). Based on the inferred genetic control of these allozymes, a survey of 239 clones of the morphological S. alba$S$. fragilis complex indicated that most of the allelic differentiation occurred at the local level of small tributaries, but that there is allelic evenness among the catchment areas of a river system (Triest et al., 1998b). Tributaries which are $10-25 \mathrm{~km}$ in length were proposed as the most likely entities for further examination of putative hybridization and events of allelic fixation. Yet, allozymes could give no evidence of extensive hybridization in the field between $S$. alba and $S$. fragilis (Triest et al., 1999).

Because phylogenetic studies of closely related taxa, or individuals within taxa, are often limited by the large number of individuals to be considered in the comparison (Stewart, 1993), a well-designed and conceptual approach has to be worked out using suitable markers. Molecular markers that discriminate between closely related taxa can be useful for estimating the extent of hybridization and introgression among species (Perron et al., 1995; Khasa \& Dancik, 1996). Substantial amounts of DNA polymorphism can be detected by PCR using single decanucleotide primers (Williams et al., 1990). Although the value of RAPDs can be questioned (e.g. Smith et al., 1994; Harris, 1995; van de Zande et al., 1995), the technique is more reliable when assaying by a considerable number of primers and selecting a few repeatable and clearly interpretable RAPD fragments (Furman et al., 1997). Analysing the heritability of the RAPD fragments in the progeny of artificial crosses undoubtedly will increase their value as molecular markers. Recently, AFLP have also proved to be useful in generating polymorphic DNA fragments for the identification of willows (Beismann et al., 1997).

The objective of this study was to estimate the extent of hybridization in the $S$. alba-S. fragilis complex through the subsequent analysis of both morphology and RAPDs in three complementary sets of samples: (i) artificially created hybrid progeny between presumed pure species in order to select appropriate RAPD markers; (ii) a morphological continuum of $S$. alba, $S . \times$ rubens and $S$. fragilis, representing a morphological hybrid index, in order to select appropriate reference clones of presumed pure species and eventually also the $\mathrm{F}_{1}$ hybrid and introgressed hybrids; and (iii) representative European reference clones of $S$. alba and $S$. fragilis in order to test the validity of the chosen species-specific markers beyond a regional scale.

\section{Materials and methods}

\section{Plant materials}

The willow buds or juvenile leaves originated from three complementary sets of sampling.

Set no. 1: controlled crosses (Table 1) of parental $S$. alba and $S$. fragilis clones originating from Belgium were first studied for morphological variation and

Table 1 Presence and absence frequencies of RAPD markers in four parental types and three progeny families resulting from interspecific crosses of Salix alba and S. fragilis clones. Because D and H are very distinct in their genotypes, their progeny was considered here as interspecific

\begin{tabular}{|c|c|c|c|c|c|}
\hline \multirow{2}{*}{\multicolumn{2}{|c|}{ Controlled crosses }} & \multicolumn{2}{|c|}{ RAPD bands } & \multirow{3}{*}{$\begin{array}{c}H_{\mathrm{o}} \\
\text { putative }(+-)\end{array}$} & \multirow[b]{3}{*}{$\% H_{\mathrm{o}}$} \\
\hline & & \multirow{2}{*}{$\begin{array}{c}\text { Present } \\
(++ \text { or }+-)\end{array}$} & \multirow{2}{*}{$\begin{array}{c}\text { Absent } \\
(--)\end{array}$} & & \\
\hline Code & Species & & & & \\
\hline \multicolumn{6}{|c|}{ Female parental types } \\
\hline A $(86.027)$ & S. $a l b a$ & 6 & 12 & 4 & $22 \%$ \\
\hline B $(86.061)$ & S. alba & 9 & 9 & 6 & $33 \%$ \\
\hline $\mathrm{D}(90.004)$ & S. fragilis & 11 & 7 & 6 & $44 \%$ \\
\hline \multicolumn{6}{|l|}{ Male parental type } \\
\hline H (90.002) & S. fragilis & 10 & 8 & 10 & $55 \%$ \\
\hline \multicolumn{6}{|l|}{ Progenies $\left(\mathrm{F}_{1}\right)$} \\
\hline Code & Female $\times$ male & $\begin{array}{l}\text { Number of } \\
\text { individuals }\end{array}$ & & & \\
\hline $\mathrm{B} \times \mathrm{H}(90.008)$ & S. alba $\times S$. fragilis & 15 & & & \\
\hline $\mathrm{D} \times \mathrm{H}(90.016)$ & S. fragilis $\times S$. fragilis & 40 & & & \\
\hline $\mathrm{A} \times \mathrm{H}(90.004)$ & S. alba $\times S$. fragilis & 14 & & & \\
\hline
\end{tabular}

$H_{\mathrm{o}}$, observed heterozygosity. 
RAPD. The clones were collected from the field in 1986 and 1990 and further cultivated at the Institute for Forestry and Game Management (IBW, Ministry of Flemish Community). The artificial interspecific crosses were performed in 1990 and the progeny were further cultivated at the IBW. The alphabetical codes of the parental types given at that time have been maintained for ease of comparison.

Set no. 2: a representative morphological continuum of $S$. alba, $S . \times$ rubens and $S$. fragilis was investigated for morphological variation and RAPD. Forty-six clones from the field (upstream tributaries of the river Schelde catchment) were collected in 1982 and grown clonally at the IBW. The clones were previously identified as belonging to a putative series of pure species and their morphological intermediates. The codes used for the hybrid index are: $\mathrm{A}=S$. alba, $\mathrm{AH}=S$. alba hybrid or introgressant, $\mathrm{R}=S$. $\times$ rubens, $\mathrm{FH}=S$. fragilis hybrid or introgressant, $\mathrm{F}=S$. fragilis.

Set no. 3: additional European reference materials were the IBW clones of $S$. alba 81.707 (cv. Bredevoort, The Netherlands), 81.708 (cv. Lievelde, The Netherlands), 81.709 (cv. Het goor, The Netherlands), 81.713 (I3.58, Italy), 81.716 (Oberer Inn 1, Germany), 81.722 (Bulg 1/64, Bulgaria) and of S. fragilis 95.002 and 95.003 (Sweden). These European clones were checked for their morphology and RAPDs against previously selected Belgian reference clones.

\section{Methods}

Morphological data The identification of the individual trees and the analysis of morphological characteristics was carried out on all samples used to set up the reference system. UPOV guidelines provided a basis for the selection of willow characteristics to be considered (De Bondt, 1996). Features were bud length, leaf length, leaf width, ratio of leaf length/leaf width, petiole length, degree of serration at leaf margin, the shape of the buds and degree of pubescence on various organs (stem, upper part of the twigs, lower half of the twigs, bud tip, upper side of the leaf and lower side of the leaf). The measurements were standardized into five classes before ordination analysis.

$D N A$ extraction and $P C R$ procedure Buds or sprouting willow leaves were collected, frozen in liquid nitrogen and stored at $-80^{\circ} \mathrm{C}$. Total plant DNA for PCR was isolated according to a slightly modified protocol from Murray \& Thompson (1980). Previously frozen plant material (up to $3 \mathrm{~g}$ ) was ground in a mortar containing liquid nitrogen. Twenty $\mathrm{mL}$ of DNA extraction buffer (100 mм Tris pH 8, $1.4 \mathrm{~m} \mathrm{NaCl}, 20 \mathrm{~mm}$ EDTA, 2\% CTAB, $1 \%$ PVPP, $1 \% \beta$-mercaptoethanol) were added and the mixture subsequently incubated at $65^{\circ} \mathrm{C}$ for $20 \mathrm{~min}$. After cooling to room temperature, $20 \mathrm{~mL}$ of chloroform-isoamylalcohol $(24: 1, \mathrm{v} / \mathrm{v})$ (CI) were added. The mixture was then centrifuged for $10 \mathrm{~min}$ at $3200 \mathrm{~g}$. After recovery of the upper phase, 0.1 vol. $10 \%$ CTAB and 1 vol. CI were added. A second centrifugation was carried out at $3200 \mathrm{~g}$ for $10 \mathrm{~min}$. $1.2 \mathrm{vol}$. precipitation buffer (100 mm Tris $\mathrm{pH}=8,20 \mathrm{~mm}$ EDTA, 2\% CTAB) was added to the recovered upper phase. After an incubation of at least $20 \mathrm{~min}$ at room temperature, the nucleic acids were pelleted for $15 \mathrm{~min}$ at $8200 \mathrm{~g}$. The pellet was dissolved in $5 \mathrm{~mL} 1 \mathrm{M} \mathrm{NaCl}$ and once fully dissolved, $10 \mu \mathrm{L}$ of a $10-\mathrm{mg} / \mathrm{mL}$ RNase solution were added. This mixture was incubated at $37^{\circ} \mathrm{C}$ for $30 \mathrm{~min}$. The DNA was precipitated by adding $500 \mu \mathrm{L} 4 \mathrm{M} \mathrm{LiCl}$ and $15 \mathrm{~mL} 100 \% \mathrm{EtOH}\left(-70^{\circ} \mathrm{C}, 30 \mathrm{~min}\right)$, followed by a centrifugation at $12800 \mathrm{~g}$ for $10 \mathrm{~min}$. The DNA pellet was washed in $70 \% \mathrm{EtOH}$. After a final centrifugation at $12800 \mathrm{~g}$ for $10 \mathrm{~min}$, the DNA pellet was dried and subsequently dissolved in $500 \mu \mathrm{L}$ TE. DNA presence was monitored by subjecting samples to $1 \%$ agarose gel electrophoresis in 1× TBE buffer (Sambrook et al., 1989) and by visual assessment of band intensities compared with DNA standards. The exact DNA concentration and the purity was determined by spectrophotometry. A set of 14 decanucleotides of arbitrary sequence (obtained from Operon Technologies Inc., Alameda, CA.) were selected according to their reproducibility from the 40 primers that were initially employed, namely OPA01, OPA02, OPA04, OPA05, OPA07, OPA14, OPA20, OPO04, OPO11, OPO12, OPO15, OPO16, OPO19, OPO20. The $25 \mu \mathrm{L}$ reaction mixture contained approximately $25 \mathrm{ng}$ template DNA, 5 pmol of a single decanucleotide, $100 \mu \mathrm{m}$ each of dNTPs (Pharmacia) and 1 unit Taq polymerase in the incubation buffer provided by the manufacturer of the enzyme (Boehringer Mannheim). The mixture was overlaid with two drops of mineral oil. Amplification was achieved in a Thermojet thermocycler (Eurogentec) programmed as follows: 1 cycle of $2 \mathrm{~min}$ at $94^{\circ} \mathrm{C} ; 40$ cycles of $45 \mathrm{~s}$ at $92^{\circ} \mathrm{C}, 1 \mathrm{~min}$ at $36^{\circ} \mathrm{C}, 2 \mathrm{~min}$ at $72^{\circ} \mathrm{C} ; 1$ cycle of $5 \mathrm{~min}$ at $72^{\circ} \mathrm{C}$. Amplification products were subjected to electrophoresis on $1 \%$ agarose gels in $1 \times$ TBE and detected by ethidium bromide staining. Molecular weights were estimated using lambda DNA (Boehringer Mannheim) digested with PstI (Eurogentec). At least three repeat reactions were analysed for all primers on every individual.

Data analysis The reproducibility of the amplification products was improved by altering the concentrations of $\mathrm{Mg}^{2+}$, Taq polymerase and the amount of template and primer DNA. In order to verify that the plant organs do not affect individual amplification products, extractions 
were performed on buds (October-January), young leaves (March) and older leaves (September-October). No differences were found between the amplification products from the same individual. Reliability of the amplification products was also tested using two different DNA thermal cyclers, using the same temperature profiles, obtaining nearly completely matching amplified bands. Sometimes, the minor bands were difficult to interpret, but if such fragments were clearly visualized in one of the repeats, they were considered as present. Principal coordinate analysis (PCOORDA) was carried out using the NTSYS-PC program (Rohlf, 1993). Banding patterns for all primers were compiled and introduced as a single rectangular data matrix consisting of presence/ absence data. The data set was then transformed into a similarity matrix using the simple matching (SM) coefficient of resemblance.

\section{Results}

\section{Morphological variability}

From the analysis of the morphological characteristics of buds, leaves and twigs, no clearly separated groups of species or hybrids could be revealed in the progeny of controlled crosses, the representative clones of the hybrid index and the European reference clones. The PCOORDA analysis indicated that there are numerous intermediate positions between the more extreme groups along the first principal coordinate. Therefore, only $27 \%$ and $7 \%$ of the morphological variation in the interspecific progeny could be explained by the first and second principal coordinate, respectively (Fig. 1). When checking the position of the controlled crosses, it became clear that the progeny where the male $S$. fragilis parent $\mathrm{H}$ was

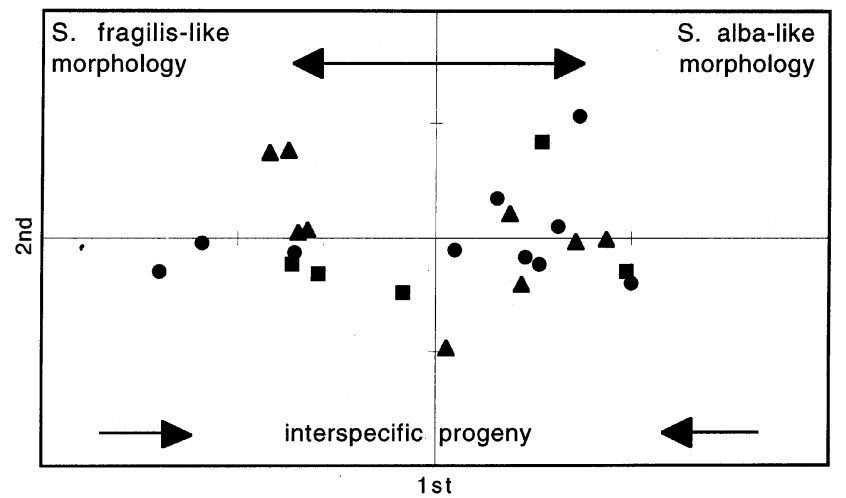

Fig. 1 Principal coordinate analysis of morphological variation in the Salix alba-S. fragilis complex using the progeny of interspecific controlled crosses, namely $\mathrm{B} \times \mathrm{H}$ (triangles), $\mathrm{A} \times \mathrm{H}$ (squares) and $\mathrm{D} \times \mathrm{H}$ (circles). A large morphological variability is noted in the three families. involved was morphologically very variable. The interspecific $\mathrm{A} \times \mathrm{H}$ and $\mathrm{B} \times \mathrm{H}$ families had progenies with intermediate forms as well as with $S$. alba morphology. The $\mathrm{D} \times \mathrm{H}$ family had progeny ranging morphologically from $S$. fragilis through intermediate forms to $S$. alba. The latter might indicate that the status of the parental type $\mathrm{H}$ is not a pure $S$. fragilis but already an $\mathrm{F}_{1}$ or introgressed hybrid. Therefore, $\mathrm{D} \times \mathrm{H}$ was considered as an inter- rather than an intraspecific cross for this analysis. In the representative clones of the hybrid index (Fig. 2), the S. fragilis (F) and so-called introgressed $S$. fragilis hybrids $(\mathrm{FH})$ could be identified rather consistently, whereas there could be more confusion among the $S$. alba (A), $S . \times$ rubens $(\mathrm{R})$ and the so-called introgressed $S$. alba hybrids (AH). Only $21 \%$ and $9 \%$ of the variation could be explained by the first two axes. The previously chosen reference material of $S$. fragilis (Sweden) and S. alba (The Netherlands, Germany, Italy and Bulgaria) were at opposite positions (Fig. 3) and confirmed the potential use of the morphological characters for identifying both species and eventually their putative hybrids. As a result of the comparison with introgressed $S$. alba clones, only $26 \%$ and $10 \%$ of the variation could be explained by the first two axes.

\section{RAPDs of controlled crosses (set no. 1)}

A total of 19 parental specific amplification products were selected out of 86 amplification products, using 13 primers (OPA01, OPA02, OPA04, OPA05, OPA07, OPA14, OPA20, OPO04, OPO11, OPO12, OPO15, OPO16, OPO19). Estimation of the proportion of heterozygous RAPDs in the parental types through

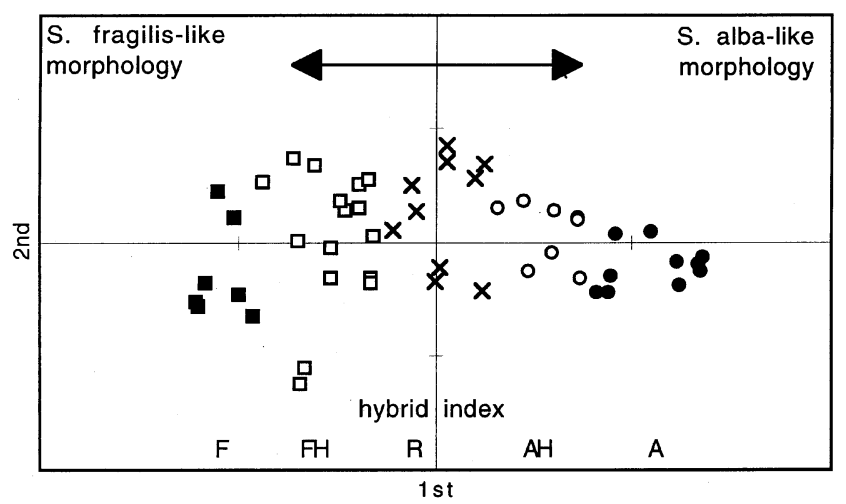

Fig. 2 Principal coordinate analysis of morphological variation in the Salix alba-S. fragilis complex using a putative series of pure species and hybrids. These Belgian clones were used to set up an arbitrary hybrid index going from pure $S$. fragilis (F, closed squares), introgressed $S$. fragilis $(\mathrm{FH}$, open squares), putative hybrids ( $\mathrm{R}$, crosses), introgressed S. alba (AH, open circles) and pure $S$. alba (A, closed circles). 
comparison of the presence/absence status for each amplification product in their progeny revealed that $S$. alba had more absence codes than $S$. fragilis and consequently a lower proportion of observed heterozygosity $\left(H_{\mathrm{o}}\right)$. The male parental type $\mathrm{H}$ of $S$. fragilis was heterozygous for all 10 of the markers used (Table 1). $\mathrm{H}$ thus could be close to an $\mathrm{F}_{1}$ in origin, explaining the large variability in the progeny.

All of the selected fragments were diagnostic of the individual parental types. Samples with a missing value were left out of the analysis presented here, because this might influence the position of the intermediates in an ordination analysis (Fig. 4). All crosses resulted in

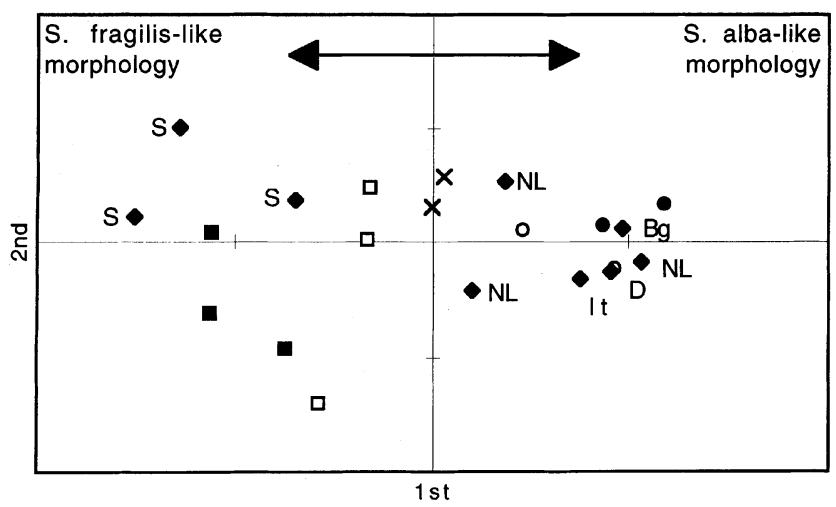

Fig. 3 Principal coordinate analysis of the morphological variation in the Salix alba-S. fragilis complex using putative pure clones of $S$. fragilis (S, Sweden) and of $S$. alba

(Bg, Bulgaria; D, Germany; It, Italy; and NL, The Netherlands). They were placed against a series of the arbitrary hybrid index (same symbols as in Fig. 2).

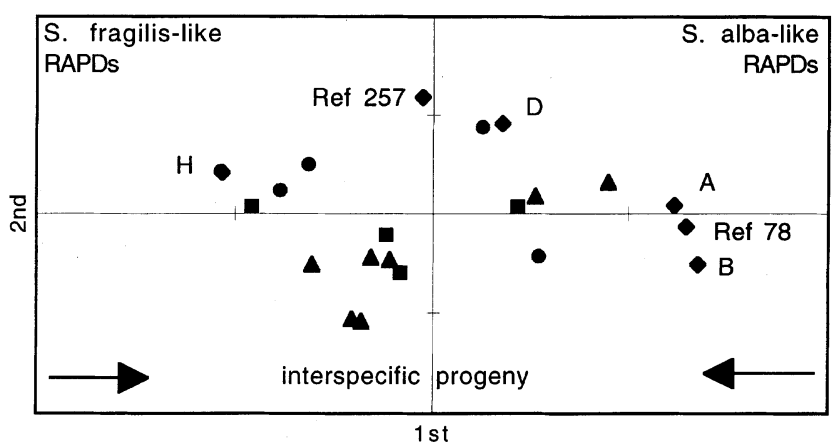

Fig. 4 Principal coordinate analysis of an analysis of speciesdiagnostic RAPD variation in amplification products among the families of controlled interspecific crosses. The progeny of interspecific crosses are occupying intermediate positions $(\mathrm{B} \times \mathrm{H}$ (triangles) $\mathrm{A} \times \mathrm{H}$ (squares) and $\mathrm{D} \times \mathrm{H}$ (circles)) Note the deviating identity of the Salix fragilis parental types D and $\mathrm{H}$ and the close relationship of the $S$. alba parents A and B. The samples were checked against a reference clone for $S$. alba (78) and an introgressed S. fragilis (257). progeny with a variable genotype composition. Only $20 \%$ and $16 \%$ of the variation could be explained by the first and second principal coordinates, respectively. The most important observation for the further analysis of the hybrid $S$. alba-S. fragilis complex is that the majority of the progeny resulting from interspecific crosses between genotypically distinct parental types, were positioned in the intermediate zone and in between the parents. A minority of the progeny had multi-RAPD genotypes similar to one of the parental types.

\section{RAPDs of a representative morphological continuum (set no. 2)}

A total of 13 species-diagnostic amplification products were selected from the 95 DNA fragments obtained with 12 primers (OPA02, OPA04, OPA05, OPA14, OPA20, OPO04, OPO11, OPO12, OPO15, OPO16, OPO19, OPO20). The reduction from 19 to 13 fragments was necessary because some markers varied between individuals in the previous analysis of the controlled crosses. A PCOORDA analysis of 46 willow trees for these 13 amplification products using the simple matching coefficient revealed that in this collection there were clearly two major groups corresponding to either $S$. alba or S. fragilis (Fig. 5). About $72 \%$ of the variation could be explained by the first principal coordinate (only $8 \%$ for the second axis). As such, the morphological variability of $10 \mathrm{~S}$. alba, $10 \mathrm{~S}$. alba hybrids, $10 \mathrm{~S} . \times$ rubens, 10 $S$. fragilis hybrids and six $S$. fragilis was not reflected by these species-diagnostic genotypes.

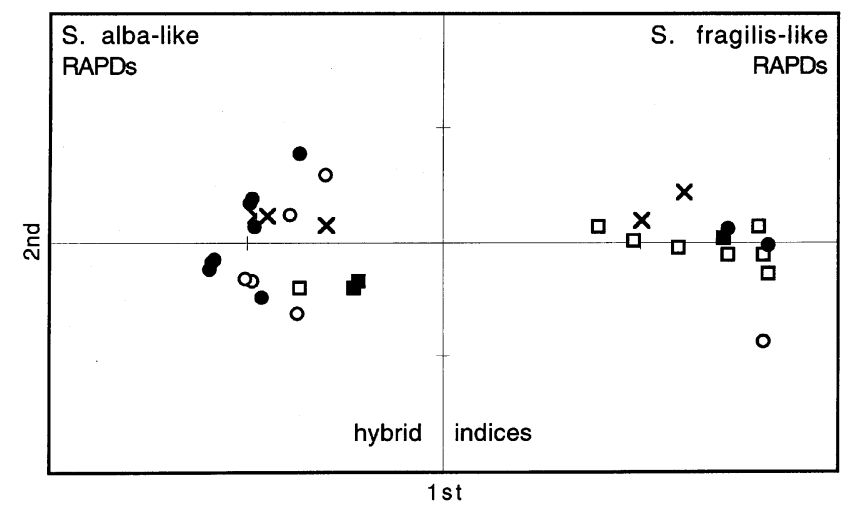

Fig. 5 Principal coordinate analysis of species diagnostic RAPDs among Belgian clones of the Salix alba-S. fragilis complex, using 46 individuals from a gradual series of morphologically intermediate types. The RAPD-based genotypes did not reflect such a gradual relationship but indicated two clearly separated gene pools. The clones at the extreme positions along the first principal coordinate were selected as references for further comparisons (same symbols as in Fig. 2). 


\section{RAPDs in representative European clones (set no. 3)}

The genetic similarity between individual clones of diverse European origin and the selected Belgian reference clones was calculated using the same 13 diagnostic amplified products as in set no. 2. The similarity values were the lowest between individuals of the putative pure $S$. alba and the putative pure $S$. fragilis. Within a species, the lowest similarity values were $62 \%$ (for S. alba) and $46 \%$ (for S. fragilis). Noteworthy is that the most deviating $S$. fragilis (IBW no. 257) was more similar in these DNA fragments to $S$. fragilis from Sweden $(62 \%)$ than to all other samples. The Swedish willows, however, are more similar to all other $S$. fragilis samples than to IBW no. 257. The most deviating S. alba (IBW no. 100) had its lowest similarity $(15 \%)$ to the IBW no. 257 and to those from Sweden (39\%), but was more related to all other samples by over $50 \%$.

The PCOORDA revealed two clearly different clusters, each corresponding to $S$. alba or $S$. fragilis (Fig. 6). About $77 \%$ of the variation on the first axis can be explained by the species specificity and positioned the reference clones as such, regardless of the origin. Only the clone from Bulgaria was slightly differentiated from S. alba. The samples nos. 100 and 257, most differentiated from the S. alba and S. fragilis references, respectively, were placed towards intermediate positions along the first principal coordinate but became separated along the second axis (explaining another $12 \%$ of the variation). They were included to frame the possible

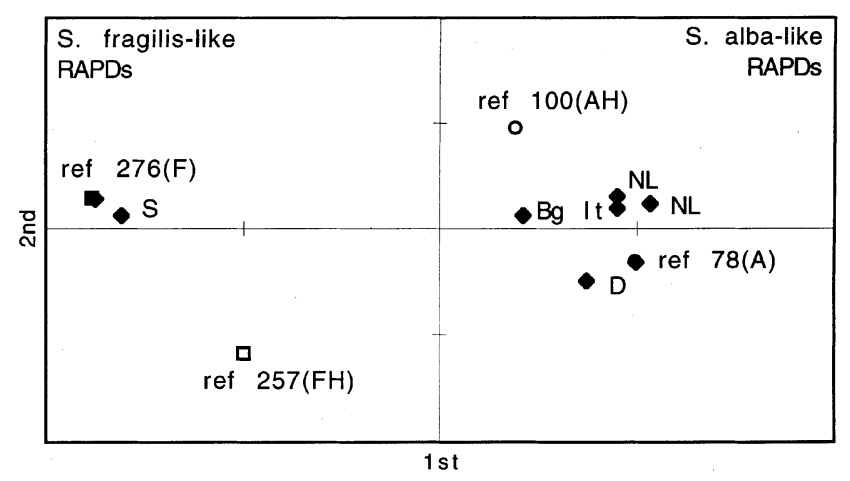

Fig. 6 Principal coordinate analysis of species-diagnostic RAPDs in putative pure clones of Salix fragilis (S, Sweden) and of $S$. alba (Bg, Bulgaria; D, Germany; It, Italy; and NL, The Netherlands). The previously selected references clones from Belgium were nos 276 (S. fragilis), 257 (introgressed S. fragilis), 78 (S. alba) and 100 (introgressed $S$. alba). The selected references are clearly grouped according to the species, illustrating that the chosen method also could be applicable on a larger European scale. variability (putative remnants of introgressed individuals) within each species.

\section{Discussion}

The morphological analysis of the leaves, buds and twigs indicated that there are many potential hybrids in the samples. This confirmed the observations of many botanists (Rechinger, 1964; De Langhe et al., 1983) that the majority of the willows of the $S$. alba-S. fragilis complex are hybrids and introgressants. Together with the ease of artificial cross-fertilization between both species this has even led to the suggestion that almost no pure species were available in the field as a result of repeated introgression. Most of the quantitative morphological characteristics do not have a clear diagnostic value but are based on a continuous variation in the degree of pubescence of the twigs, buds and leaves. Obviously, the identification of the least pubescent individuals ( $S$. fragilis-like) can be achieved more consistently than of the more pubescent $S . \times$ rubens and S. alba.

If the parental type $\mathrm{H}$ of $S$. fragilis is an introgressant in origin, then the variation of its progeny can be better understood. Similarly, all other individuals at an intermediate position of the ordination could be regarded as potential hybrids. The large proportion of morphological intermediates suggests that hybridization is a common process between the species and that they coexist as a hybrid complex. When comparing the morphological variation of the progeny with RAPDs, using 19 diagnostic fragments at the level of the individual parental types, it becomes clear that the more qualitatively chosen fragments in the parental types are providing sufficient information about the relationships between the offspring and their parents. For the analysis of artificial hybrids, particular marker genes are better suited than morphology. In progeny studies, the availability of good markers is more important than the total amount of fragments considered. The use of a few but unambiguous diagnostic bands gave clear information on marker segregation and estimations of heterozygosity in these dominant markers. The large genetic variability of the progeny where $\mathrm{H}$ is involved as a male parent of $S$. fragilis is consistent with the data on the morphological variability though not on an individual basis. RAPDs were also reliable for showing that a large portion of the amplification products were heterozygous in most of the parental types. It thus can be expected that extensive outcrossing between different genotypes should lead to a broad variability in the clones from the field. However, this broad variability seems not to be the case in the present sampling or in a previous study (Triest et al., 1997). 


\section{Genetic differentiation vs. continuum in morphology}

Using a morphological continuum of 46 clones, it was possible to trace those trees that were at the largest genetic distance within the collection by means of comparing the original data from a similarity matrix and by using a PCOORDA. Much of the variation could be explained in terms of a $S$. alba-like and $S$. fragilis-like grouping. Most samples were genetically close to the presumed references. In this collection of 46 trees, representing a hybrid index, there were no samples observed with clear intermediate values of genetic similarities.

A useful comparison of the morphological identity with the RAPDs of a previously investigated series of the S. alba-S. fragilis complex (Triest et al., 1997) showed that $41 \%$ of the individuals had a genotype and morphology both corresponding to $S$. alba but that $23 \%$ had a genotype typical of $S$. alba, but with a $S$. fragilis morphology. Similarly, $28 \%$ of the individuals had a genotype and morphology corresponding to $S$. fragilis but $8 \%$ had a genotype typical of $S$. fragilis and a morphology typical of $S$. alba. Because the progeny of controlled crosses were ordinated at positions between the parental types if these parents were genetically divergent, then the putative $F_{1}$ or introgressed hybrids (if they exist) from the field also should be positioned as intermediates.

It might be questioned whether the comigrating bands of individuals, originating from such different biogeographical regions, are really homologous. Nonhomology might introduce noise into the data set, eventually leading to inaccurate estimates of genetic relationships. Rieseberg (1996) reviewed this problem and it can be shown that the chance for nonhomology is increased with larger genetic distances and when introducing large randomly generated data sets. Because the selection of homologous amplification products was initially inferred from the controlled crosses of Salix, it can be argued that, in the case of full-sibs, the comigrating fragments are indeed homologous for the samples from Belgium. Closely related individuals exhibiting a large (dominant) allelic evenness presumably were less prone to RAPD artefacts. Allozymes in a similar set of $S$. alba-S. fragilis clones from Belgium revealed a large allelic evenness without unique alleles in different regions (Triest et al., 1998b).

The additional willow trees from other European origins are clustered unambiguously among the presumed pure species of $S$. alba and $S$. fragilis of the Belgian clones. It is evident that if the morphological identification of the Belgian clones was correct, the 13 diagnostic amplification products used here also had to be species-specific on a larger European scale, which was demonstrated here. The observation that the abovementioned European clones of putative pure $S$. alba or $S$. fragilis were genetically very close to the putative pure Belgian clones might be indicative of a more widespread genetic evenness within both species, as well as of the genetic characteristics of the species. The latter are thus most likely conservative over a large geographical area. When comparing the European references to the data obtained from the Belgian clones, previously used to set up a reference system (Triest et al., 1997), it becomes evident that the genetic composition of the $S$. alba$S$. fragilis complex is disrupted, being skewed towards the pure species and not towards intermediate hybrid forms. This dominating process, namely a low probability of hybrid formation and maintenance, could also explain why the species have kept their genetic identities quite well over such a large geographical area. The possible role of introgression can be explained as an additional source of genetic variation. Hybridization and introgression increase the opportunities of recombination by bringing together differentiated genomes. If these genomes are coadapted, recombination is unlikely to produce successful new variants, except perhaps in a disturbed or changing environment. Many hybrid zones, however, appear to represent substantial barriers (in a so-called tension zone) to gene exchange, with limited introgression occurring in the face of selection against hybrids or recombinants.

Morphological observations do not always correspond with molecular analyses in the case of putative hybrids (Rieseberg \& Brunsfeld, 1992; Nason et al., 1992; Dawson et al., 1996). The utility of RAPDs in suggesting interspecific hybridization was clearly demonstrated in Gliricidia where additional RFLPs revealed allelic combinations consistent with a hybrid origin at similar localities (Dawson et al., 1996). The Poptun individuals of Gliricidia were heterozygous at two RFLP loci and strongly indicated $F_{1}$ hybrids. The observation that the suggested $F_{1}$ hybrids were positioned as intermediates along the first principal coordinate of the PCOORDA, but grouped separately along the second principal coordinate is quite similar to our observations on willows. Morphology and isozymes indicated a close relationship between Solidago albopilosa and S. Alexicaulis, whereas RAPDs on $\mathrm{F}_{1}$ hybrids indicated that $S$. flexicaulis only hybridizes with S. caesia (Esselman \& Crawford, 1997). Phylogenetic relationships in 19 species of Rosa apparently showed good correlation with previous classifications based on morphological and karyological studies (Millan et al., 1996).

Similarly, allozymes do not always follow morphological variation. In Aesculus (De Pamphilis \& Wyatt, 
1989) and Populus (Keim et al., 1989) hybridization could be detected on the basis of diagnostic features. In Quercus rubra and Q. ellipsoides, morphological hybrids were observed but the isozyme polymorphism was similar in both species (Hokanson et al., 1993). In an outcrossing perennial (Ipomopsis), putative hybridization was noted in the morphology, but again, the allozyme composition remained very similar among three species of a complex (Wolf et al., 1991).

In some cases, molecular markers reveal hybrid forms that were not expected on morphological grounds. The detection of hybrids and introgressed individuals between black spruce and red spruce was more efficient using molecular (RAPD) markers than with morphological traits (Perron \& Bousquet, 1997). Their morphological discriminant model, based on twig characters, misclassified as parental types many of the hybrid or introgressant trees detected with molecular markers. They observed a higher proportion of hybrids with RAPDs than with morphology, which led them to state that natural hybridization is a rule rather than an exception. In contrast, our results on the willows demonstrate that morphological traits indicate a higher level of hybrid formation than do the RAPD markers. This might be explained by the mixed reproductive strategy in willows, that is in contrast to the highly sexually reproducing spruces. Perhaps chloroplast DNA markers are more promising for detecting interspecific gene flow, as shown for American white oaks (Whittemore \& Schaal, 1991).

Both species of willows studied here may have populations that are structured largely independently. It might be expected that $S$. fragilis is more clonal than $S$. alba. If so, multiple local contacts would provide the only opportunity for many hybridization events. Such mosaic hybrid zones are logical places to look for intermediate variants. Beismann et al. (1997) most likely observed such a local contact zone between $S$. alba and $S$. fragilis with hybridization as a result. Clonality, however, must have influenced the genetic structuring of the mixed population, because they collected $S$. fragilis mainly at the higher altitudes and $S$. alba at the lower altitudes. Surprisingly, the presumed hybrids they detected with AFLP markers seemed to be rather homogeneous, suggesting that they were $F_{1}$ hybrids rather than introgressed ones. Local mosaic patterns could be tension zones of coadapted gene complexes, although hybrid zones often have been reported to remain narrow, with a low frequency of introgressive hybrids (Harrison, 1990).

The present study could indicate that identification of morphological hybrids is not necessarily following the chosen species-specific RAPD amplification products. Hybridization in the $S$. alba-S. fragilis complex is suggested to be a process with a low occurrence in the lowlands of Belgium.

\section{Acknowledgements}

This project was funded by the Fund for Scientific Research, Flanders (mandate of Senior Research Associate and contract no. S2/5-ID.E 53 on ecogenetic diversity in plant populations), the Ministry of the Flemish Community (Dienst Bos en Groen, contract nos $\mathrm{WB} / 10 / 94$ and $\mathrm{BG} / 17 / 95$ on genetic diversity in tree species) and the Vrije Universiteit Brussel (OZR funding). Special thanks to Dirk Vanden Bossche for technical assistance and to Els Coart (Institute for Forestry and Game Management, Ministry of the Flemish Community) for providing the controlled crosses and the reference clones.

\section{References}

BEISMANN, H., BARKER, J. H. A., KARP, A. AND SPECK, T. 1997. AFLP analysis sheds light on distribution of two Salix species and their hybrid along a natural gradient. Mol. Ecol., 6, 989-993.

BRUNSFELD, S. J., SOLTIS, D. E. AND SOLTIS, P. S. 1991. Patterns of genetic variation in Salix section Longifoliae (Salicaceae). Am. J. Bot., 78, 855-869.

DAWSON, I. K., SIMONS, A. J., WAUGH, R. AND POWELL, W. 1996. Detection and pattern of interspecific hybridization between Gliricidia sepium and G. maculata in Meso-America revealed by PCR-based assays. Mol. Ecol., 5, 89-98.

DE BONDT, R. 1996. Role of Genetic Diversity and Identity in Replantations - Case Study on Salix sp. MSc Thesis, Vrije Universiteit, Brussel.

DE LANGHe, J., Delvosalle, L., DUVigneAud, J., LAMBinon, J. AND VANDEN BERGHEN, C. 1983. Flora Van België, Het Groothertogdom Luxemburg, Noord-Frankrijk en de aangrenzende Gebieden. Nationale Plantentuin, Meise.

DE PAMPHILIS, C. AND WYATT, R. 1989. Hybridization and introgression in Buckeyes (Aesculus: Hippocastanaceae): a review of the evidence and a hypothesis to explain longdistance gene flow. Syst. Bot., 14, 593-611.

ESSELMAN, E. J. AND CRAWFORD, D. J. 1997. Molecular and morphological evidence for the origin of Solidago albopilosa (Asteraceae), a rare endemic of Kentucky. Syst. Bot., 22, 245-257.

FURMAN, B. J., GRATTAPAGLIA, D., DVORAK, W. S. AND O'MALLEY, D. M. 1997. Analysis of genetic relationships of central American and Mexican pines using RAPD markers that distinguish species. Mol. Ecol., 6, 321-331.

HAMRICK, J. L. AND GODT, M. J. 1989. Allozyme diversity in plant species. In: Brown, A. H. D., Clegg, M. T., Kahler, A. L. and Weir, B. S. (eds) Plant Population Genetics, Breeding and Genetic Resources, pp. 43-63. Sinauer, Sunderland, MA.

HARRIS, S. A. 1995. Systematics and randomly amplified polymorphic DNA in the genus Leucaena (Leguminosae, Mimosoideae). Pl. Syst. Evol., 197, 195-208. 
HARRISON, R. G. 1990. Hybrid zones: windows on evolutionary process. In: Futuyma, D. and Antonovics, J. (eds) Oxford Surveys in Evolutionary Biology, 7, 69-128, Oxford University Press.

HOKANSON, S. C., ISEBRANDS, J. G., JENSEN, R. J. AND HANCOCK, J. F. 1993. Isozyme variation in oaks of the Apostle Islands in Wisconsin: genetic structure and levels of inbreeding in Quercus rubra and Q. ellipsoidalis (Fagaceae). Am. J. Bot., 80, 1349-1357.

KeIM, P., PAIGe, K. N., WhithaM, T. G. AND LARK, K. G. 1989. Genetic analysis of an interspecific hybrid swarm of Populus: occurrence of unidirectional introgression. Genetics, 123, $557-565$.

KHASA, P. D. AND DANCIK, B. P. 1996. Rapid identification of white Engelmann spruce species by RAPD markers. Theor. Appl. Genet., 92, 46-52.

MILLAN, T., OSUNA, F., COBOS, S., TORRES, A. M. AND CUBERO, J. I. 1996. Using RAPDs to study phylogenetic relationships in Rosa. Theor. Appl. Genet., 92, 273-277.

MURRAY, M. AND THOMPSON, w. 1980. Rapid isolation of high molecular weight plant DNA. Nucl. Acids Res., 8, 4321.

NASON, J. D., ELLSTRAND, N. C. AND ARNOLD, M. L. 1992. Patterns of hybridization and introgression in populations of oaks, manzanitas and irises. Am. J. Bot., 79, 101-111.

PERRON, M. AND BOUSQUET, J. 1997. Natural hybridization between black spruce and red spruce. Mol. Ecol., 6, 725-734.

PERron, M., GORDON, A. AND BOUSQUET, J. 1995. Speciesspecific RAPD fingerprints for the closely related Picea maritima and P. rubens. Theor. Appl. Genet., 91, 142-149.

PURDY, B. G. AND BAYER, R. J. 1995. Allozyme variation in the Athabasca sand dune endemic, Salix silicola, and the closely related widespread species, S. alaxensis. Syst. Bot., 20, 179190.

RECHINGer, K. H. 1964. Salicaceae. In: Tutin, T. G., Heywood, V. H., Burges, N. A., Valentine, D. H., Walters, S. M. and Webb, D. A. (eds) Flora Europaea, vol. 1, pp. 43-55. Cambridge University Press, Cambridge.

RIESEBERG, L. H. 1996. Homology among RAPD fragments in interspecific comparisons. Mol. Ecol., 5, 99-105.

RIESEBERG, L. H. AND BRUNSFELD, S. J. 1992. Molecular evidence and plant introgression. In: Soltis, D. E., Soltis, P. S. and Doyle, J. J. (eds) Plant Molecular Systematics, pp. 151-176. Chapman \& Hall, New York.
ROHLF, F. J. 1993. NTSYS-PC. Numerical taxonomy and multivariate analysis system, version 1.80. Exeter Software, Applied Biostatistics Inc., New York.

SAMBROOK, J., FRITSCH, E. F. AND MANIATIS, T. 1989. Molecular Cloning: A Laboratory Manual, 2nd edn. Cold Spring Harbor Laboratory Press, NY.

SMITH, J. J., SCOTT-CRAIG, J. S., LEADBETTER, J. R., BUSH, G., ROBERTS, D. L. AND FULLBRIGHT, D. W. 1994. Characterization of random amplified polymorphic DNA (RAPD) products from Xanthomonas campestris and some comments on the use of RAPD products in phylogenetic analysis. Mol. Phylogenet. Evol., 3, 135-145.

STEWART, C. 1993. The powers and pitfalls of parsimony. Nature, 361, 603-607.

TRIEST, L., DE GREEF, B., DE BONDT, R., VANDEN BOSSCHE, D., D'HAESELEER, M., VAN SLYCKEN, J. ET $A L$. 1997. Use of RAPD markers to estimate hybridization in Salix alba and Salix fragilis. Belg. J. Bot., 129, 140-148.

TRIEST, L., DE GREEF, B., D'HAESELEER, M., ECHCHGADDA, G., VAN SLYCKEN, J. AND COART, E. 1998a. Variation and inheritance of isozyme loci in controlled crosses of Salix alba and Salix fragilis. Silvae Genet., 47, 88-94.

TRIEST, L., DE GREEF, B., VAN SLYCKEN, J. AND COART, E. 1998 b. Isozyme differentiation between sympatric clones of Salix alba and Salix fragilis. For. Genet., 5, 249-260.

TRIEST, L., DE GREEF, B., VERMEERSCH, S., VAN SLYCKEN, J. AND COART, E. 1999. Genetic variation and putative hybridisation in Salix alba and Salix fragilis: Evidence from allozyme data. Pl. Syst. Evol., 215, 169-187.

VAN DE ZANDE, L., BIJLSMA, R. AND VAN DE ZANDE, L. 1995. Limitations of the RAPD technique in phylogeny reconstruction in Drosophila. J. Evol. Biol., 8, 645-656.

WHITTEMORE, A. T. AND SCHAAL, B. A. 1991. Interspecific gene flow in oaks. Proc. Natl. Acad. Sci. U.S.A., 88, 2540-2544.

WILLIAMS, J. G. K., KUBELIK, A. R., LIVAK, K. J., RAFALSKI, J. A. AND TINGEY, S. V. 1990. DNA polymorphisms amplified by arbitrary primers are useful as genetic markers. Nucl. Acid Res., 18, 6531-6535.

WOLF, P. G., SOLTIS, P. S. AND SOLTIS, D. E. 1991. Genetic relationship and patterns of allozyme divergence in the Ipomopsis aggregata complex and related species (Polemoniaceae). Am. J. Bot., 78, 515-526. 